\title{
Atenção primária à saúde na América do Sul em perspectiva comparada: mudanças e tendências
}

\author{
Primary health care in South America in comparative perspective: changes and trends \\ Adelyne Maria Mendes Pereira', Ana Luisa Barros de Castro², Rafael Antonio Malagón Oviedo³, \\ Ludmila Gonçalves Barbosa ${ }^{4}$, Camila Duarte Gerassi ${ }^{5}$, Ligia Giovanella ${ }^{6}$
}

\author{
'Doutoranda em Saúde Pública pela \\ Escola Nacional de Saúde Pública/ \\ Fundação Oswaldo Cruz (ENSP/ \\ FIOCRUZ) - Rio de Janeiro (RJ), Brasil. \\ adelynep@ensp.fiocruz.br \\ ${ }^{2}$ Doutoranda em Saúde Pública pela \\ Escola Nacional de Saúde Pública/ \\ Fundação Oswaldo Cruz (ENSP/ \\ FIOCRUZ) - Rio de Janeiro (RJ), Brasil. \\ analuisasb@yahoo.com.br \\ ${ }^{3}$ Professor da Universidade Nacional de \\ Colômbia - Bogotá, Colômbia. \\ ramalagono@unal.edu.co \\ ${ }^{4}$ Mestranda em Saúde Pública pela \\ ENSP/FIOCRUZ - Rio de Janeiro (RJ), \\ Brasil. \\ ludmilabarbosa@ensp.fiocruz.br \\ ${ }^{5}$ Mestranda em Saúde Pública pela \\ ENSP/FIOCRUZ - Rio de Janeiro (RJ), \\ Brasil. \\ miladuart@yahoo.com.br \\ ${ }^{6}$ Doutora em Saúde Pública pela \\ ENSP/FIOCRUZ. Pesquisadora Titular \\ da ENSP/FIOCRUZ - Rio de Janeiro \\ (RJ), Brasil. \\ giovanel@ensp.fiocruz.br
}

RESUMO Objetivou-se compreender as principais tendências e os desafios para a organização da atenção primária à saúde (APS) na América do Sul, no marco dos processos de mudanças políticas da última década movidos pela chegada ao poder de correntes de esquerda. Trata-se de um estudo de natureza comparada, desenvolvido a partir da análise de quatro casos - Brasil, Venezuela, Bolívia e Uruguai. Evidenciou-se que o novo contexto político deslocou o foco das políticas para a universalização e para modelos assistenciais fundados em uma APS integral. Contudo, permanecem desafios relacionados ao contexto histórico institucional de cada país para a consolidação da APS como estratégia estruturante de seus sistemas de saúde.

PALAVRAS-CHAVE: Atenção primária à saúde; Sistema de atenção à saúde; América do Sul.

\begin{abstract}
This work aimed to understand the main trends and challenges in the organization of primary health care (PHC) in South America, in the context of the processes of political changes in the last decade characterized by the arising to power of left politicians. This is a comparative study, based in the analysis of four cases - Brazil, Venezuela, Bolivia and Uruguay. The results points that the new political context in these countries moved the focus of policies to universal health care models and a comprehensive PHC. Despite the fact, that remain challenges related to the historical institutional context of each country to the consolidation of PHC as a strategy for structuring health systems.
\end{abstract}

KEYWORDS: Primary health care; Health System; South America. 


\section{INTRODUÇÃO}

Este artigo teve como objetivo compreender as principais tendências na organização da atenção primária à saúde (APS) na América do Sul, no marco dos processos de mudanças políticas ocorridas na última década com a chegada ao poder de correntes de esquerda, após o chamado 'ajuste neoliberal' liderado pelas agências internacionais. A partir da análise comparada de quatro casos - Brasil, Venezuela, Bolívia e Uruguai - , buscou-se conhecer os processos de renovaçáo da APS e compreender de que maneira a estratégia pode tornar-se capaz de gerar mudanças nos sistemas de saúde como um todo e contribuir para a garantia do direito à saúde, bem como identificar limites e desafios para esta reorientação.

Nos últimos dez anos, o tema da renovação da APS tem sido destacado em documentos de agências internacionais (OPAS, 2005; WHO, 2008), bem como na literatura especializada (LABONTÉ et al., 2009). $\mathrm{O}$ movimento de renovação tem buscado resgatar as bases e objetivos da concepção de APS firmados pela Declaração de Alma Ata para, a partir deles, propor caminhos para (re)organização dos sistemas de saúde, tendo esta como eixo orientador.

Com o triunfo eleitoral de correntes de esquerda na região sul-americana, a partir dos anos 2000, estabeleceu-se um novo panorama político com efeitos evidentes sobre a configuração dos governos e, consequentemente, sobre a direção das políticas públicas. Argentina, Bolívia, Chile, Brasil, Equador, Paraguai, Uruguai e Venezuela, no primeiro decênio do século $\mathrm{XXI}$, estabeleceram agendas políticas próprias, distanciando-se, de certa forma, das medidas monetaristas e neoliberais impulsionadas pelo Banco Mundial e Fundo Monetário Internacional (FMI), dando origem a um novo discurso oficial centrado na redistribuição de renda e na justiça social, bem como nas ideias de soberania nacional, cooperação e independência regional (MOREIRA, 2007).

A nova configuração dos governos contrasta com a hegemonia política exercida por coalizóes de governos anteriores, cujos programas foram influenciados por correntes de corte neoliberal, predominantes nos anos 1990, com adoção de mecanismos de expansão e aceleração de acumulação do capital na economia mundial.
A literatura especializada indica duas prováveis razões para a emergência e continuidade dos governos de esquerda ao longo da última década em diversos países da América Latina. Em primeiro lugar, pode-se afirmar que as difíceis condiçốes socioeconômicas geradas e/ou agravadas pelas políticas neoliberais implementadas na década de 1990 foram determinantes para o desenvolvimento das condiçóes necessárias para a mudança das coalizóes políticas na direção dos governos nos anos 2000 (PARODI, 2004; LUSTIG, 2009; PANIZZA, 2009; PAUSADELA, 2010). Derivada dessa razão de caráter mais geral, um segundo argumento aponta os processos mais específicos relacionados a dois movimentos. Por um lado, ao esgotamento e crise dos regimes políticos e seus partidos políticos tradicionais em suas velhas alianças com o setor empresarial; por outro, pela qualificação de um amplo movimento social pela democracia, que tem raízes na recomposiçấo geracional das sociedades, no surgimento de novas identidades e sujeitos sociais com demandas próprias sobre o Estado, além do fortalecimento e recomposição das velhas identidades centradas em lutas pela igualdade social e econômica (PARODI, 2004; LUSTIG, 2009; PANIZZA, 2009; PAUSADELA, 2010).

Fruto desse contexto, a ascensão das correntes políticas de esquerda e centro-esquerda ao poder traz como marca o destaque às políticas sociais com ênfase na equidade e na universalidade. Ainda que existam particularidades e diferenças entre as estratégias e os mecanismos adotados para sua operacionalização, os diferentes governos salientam, no plano discursivo, o exercício efetivo dos direitos políticos e sociais como fundamento para a expansão da cidadania e dos conteúdos qualificados da democracia (ARNSON; ARMONY, 2009). Neste marco, o direito à saúde adquire um interesse especial na agenda política e póe à prova a capacidade de inovação no desenho e operaçáo da política setorial, ao passo que demanda a criação de uma nova institucionalidade, cuja principal característica é sua capacidade de interação com outros setores da política pública sob a premissa de entender o desenvolvimento como expansão da qualidade de vida e das condições materiais, simbólicas e culturais, que permitem o aprofundamento da democracia na sociedade (PAUSADELA, 2010). 


\section{METODOLOGIA}

No intuito de compreender as principais mudanças e tendências na organização da APS no novo contexto político da América do Sul, no qual correntes de esquerda se consolidaram no governo, foram analisados quatro casos: Brasil, Venezuela, Bolívia e Uruguai. Os critérios de seleção dos países envolveram a continuidade dos governos de coalizóes de esquerda/centro-esquerda no período de estudo (2000 a 2010) e a presença de mudanças constitucionais ou reformas incrementais importantes nos sistemas de saúde. O Quadro 1 apresenta uma caracterização geral dos países estudados, com dados demográficos, indicadores de saúde da população e do financiamento dos sistemas de saúde.

Trata-se de um estudo de natureza comparada que visou permitir a compreensão das diferenças e similitudes nos processos de organização da APS nos casos selecionados. A realização de estudos comparados no campo da análise de políticas públicas é relativamente recente, datando dos anos 1960/1970, embora seja uma prática bastante comum na ciência política desde seus primórdios (MENY; THOENIG, 1992). Entre as vantagens da análise comparada, os autores citam a possibilidade de aprimorar as investigaçôes mediante a transposição de hipóteses e resultados obtidos em outros campos ou contextos; de ampliar os horizontes da análise de um caso a partir das experiências de outro; e valorizar as especificidades decorrentes do contexto histórico, político-administrativo e cultural das políticas. Para Meny e Thoenig (1992), as desvantagens estão associadas à impossibilidade de se estabelecer generalizaçóes, e, sobretudo aos riscos da seduçáo de se comparar dados incomparáveis ou se subestimar características históricas e contextuais em função de resultados comparáveis.

Para a comparação entre os países, foi construída uma matriz analítica (Quadro 2) relacionando alguns elementos importantes para a análise dos sistemas de saúde (tipo de sistema; organização; financiamento; e regulação) e aspectos relevantes para a análise da APS a partir de oito dimensóes: condução; modelo de financiamento; modelo de atenção; integração na rede; intersetorialidade e ação sobre determinantes sociais; participação social; formação dos profissionais; e interculturalidade. Para atingir o objetivo proposto, este artigo se valeu de diversas fontes de informação, fazendo uso de revisão bibliográfica, análise documental, partindo dos documentos oficiais, e de dados secundários de estatísticas internacionais para descrever as características dos sistemas de saúde e APS nos países.

\section{Análise dos casos em perspectiva comparada}

As mudanças ocorridas na América do Sul após a ascensão ao poder de forças de esquerda ou centro-esquerda, na última década, representaram o início de uma ruptura com o paradigma neoliberal dominante até então e o desenvolvimento de sistemas pautados em uma concepção de saúde enquanto direito de cidadania. $\mathrm{O}$ caminho

Quadro 1. Caracterização demográfica e sanitária dos países selecionados

\begin{tabular}{|c|c|c|c|c|}
\hline Indicadores & Brasil & Bolívia & Venezuela & Uruguai \\
\hline População total (milhares) & 195.423 & 10.031 & 29.044 & 3.372 \\
\hline População urbana (percentual) & 86,5 & 66,5 & 93,4 & 92,5 \\
\hline Crescimento anual da população (percentual) & 0,8 & 1,7 & 1,6 & 0,3 \\
\hline Expectativa de vida ao nascer em anos de vida - 2009 & 73,0 & 68,0 & 75,0 & 76,0 \\
\hline Taxa de mortalidade infantil (por 1.000 nascidos vivos) - 2010 & 17,0 & 42,0 & 16,0 & 9,0 \\
\hline Taxa de mortalidade de adultos (entre 15 e 60 anos por 1.000 habitantes) - 2009 & 154 & 167 & 146 & 119 \\
\hline Gasto total em saúde como \% do PIB - 2009 & 9,0 & 5,1 & 6,0 & 7,4 \\
\hline Gasto público em saúde como \% do gasto total em saúde - 2009 & 45,7 & 65,1 & 40,0 & 63,1 \\
\hline Gasto privado em saúde como \% do gasto total em saúde - 2009 & 54,3 & 34,9 & 60,0 & 36,9 \\
\hline Gasto total em saúde per capita (PPC \$) - 2009 & 943,00 & 225,00 & 737,00 & 979,00 \\
\hline Gasto público em saúde per capita (PPC \$) - 2009 & 431,00 & 146,00 & 295,00 & 617,00 \\
\hline
\end{tabular}

Fonte: WHO, 2012.

PPC \$: paridade do poder de compra 
rumo ao aprofundamento das tendências universalistas no campo da saúde foi diferente nos países analisados, apresentando-se em graus variados.

Dentre os casos estudados, o Brasil foi o primeiro a instituir um sistema público de caráter universal, preocupado em assegurar o acesso integral e equânime aos serviços de saúde como um direito de cidadania (BRASIL, 1988; 1990). No final dos anos 1990, a Venezuela instituiu um Sistema Público Nacional de Saúde (SPNS) de cunho universal, intersetorial, descentralizado e participativo (VENEZUELA, 1999). Contudo, a transição do modelo de Seguro Social para a Seguridade Social ainda se mantém em curso nesse país, configurando um sistema segmentado. Pode-se afirmar que o SPNS tem se desenvolvido em torno dos Programas Misión Barrio Adentro I y II, como será discutido a seguir.
Diferentemente dos demais casos estudados, a Constituição do Uruguai não garantiu a saúde enquanto direito de toda a população, o que foi estabelecido em 2007 através da Lei no 18.211, que criou o Sistema Nacional Integrado de Saúde (SNIS). O SNIS articula prestadores integrais públicos e privados com o objetivo de garantir cobertura universal e atenção integral à saúde, por meio da incorporação progressiva de grupos populacionais ao sistema (ISAGS, 2011). Ao final dos anos 2000, a Bolívia instituiu o Sistema Nacional de Saúde (SNS) de caráter universal (BOLÍVIA, 2009), já tendo iniciativas em direção à Saúde da Família e da Comunidade Intercultural (SAFCI) desde 2008. Todavia, o modelo de asseguramento diversificado permanece vigente, em detrimento do acesso público universal.

\begin{tabular}{|c|c|c|c|c|}
\hline \multirow{5}{*}{ 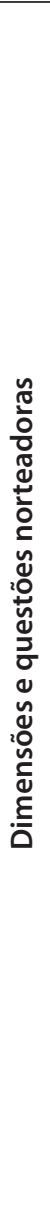 } & \multicolumn{4}{|c|}{ Caracterização dos sistemas públicos de saúde } \\
\hline & $\begin{array}{l}\text { Tipo de sistema } \\
\text { - } \quad \text { Como o sistema se } \\
\text { expressa no marco legal } \\
\text { e constitucional? } \\
\text { - } \quad \text { Quem é coberto pelo } \\
\text { sistema? } \\
\text { Qual o modelo de } \\
\text { vinculação ao sistema de } \\
\text { saúde (asseguramento } \\
\text { ou direito de cidadania)? }\end{array}$ & $\begin{array}{l}\text { Organização do sistema: } \\
\text { prestação de serviços, } \\
\text { integração entre os níveis do } \\
\text { sistema e participação social } \\
\text { - } \quad \text { Quais as } \\
\text { responsabilidades de } \\
\text { cada esfera de governo? } \\
\text { - Como está organizada a } \\
\text { rede assistencial? } \\
\text { Quais são os } \\
\text { mecanismos de } \\
\text { articulação, integração e } \\
\text { controle do sistema? } \\
\text { Qual o papel do setor } \\
\text { privado? }\end{array}$ & $\begin{array}{l}\text { Financiamento } \\
\text { - Quem financia o sistema } \\
\text { público de saúde? } \\
\text { Quais são as fontes de } \\
\text { financiamento? } \\
\text { - Qual o percentual de } \\
\text { gasto privado no total } \\
\text { de gasto em saúde? } \\
\text { Qual o gasto total e o } \\
\text { gasto público em saúde } \\
\text { per capita? } \\
\text { Há copagamento no } \\
\text { setor público? }\end{array}$ & $\begin{array}{l}\text { Regulação } \\
\text { - } \quad \text { Quais as principais } \\
\text { estratégias de regulação } \\
\text { nos seguintes campos: } \\
\text { - } \quad \text { Regulação do sistema } \\
\text { de saúde; Regulação de } \\
\text { - } \quad \text { Rerviços de saúde; } \\
\text { - } \quad \text { Regulação sanitária; } \\
\text { Regulação de mercado. }\end{array}$ \\
\hline & \multicolumn{4}{|c|}{ Caracterização da atenção primária à saúde nos sistemas sanitários } \\
\hline & $\begin{array}{l}\text { Concepção de APS } \\
\text { • } \quad \text { Qual a concepção de } \\
\text { APS predominante? } \\
\text { • Qual o papel da APS no } \\
\text { sistema de saúde? }\end{array}$ & $\begin{array}{l}\text { Alocação dos recursos para APS } \\
\text { - Qual a participação dos } \\
\text { entes governamentais no } \\
\text { financiamento da APS? } \\
\text { - Há copagamento na APS? }\end{array}$ & $\begin{array}{l}\text { Modelo de atenção } \\
\text { - } \quad \text { Qual a estratégia } \\
\text { predominante para a } \\
\text { organização da APS? } \\
\text { - } \quad \text { Quais os tipos de serviços } \\
\text { disponíveis na APS? } \\
\text { - } \quad \text { Quais profissionais } \\
\text { atuam na APS? }\end{array}$ & $\begin{array}{l}\text { Integração na rede } \\
\text { - } \quad \text { Qual o papel da APS na } \\
\text { rede de serviços de saúde? }\end{array}$ \\
\hline & $\begin{array}{l}\text { Intersetorialidade e ação } \\
\text { sobre determinantes sociais } \\
\cdot \quad \text { Há conselhos e fóruns } \\
\text { intersetoriais/(inter) } \\
\quad \text { governamentais? }\end{array}$ & $\begin{array}{l}\text { Participação social } \\
\text { • Há conselhos de saúde } \\
\text { locais com participação } \\
\text { comunitária no } \\
\text { planejamento da APS? }\end{array}$ & $\begin{array}{ll}\text { Formação dos profissionais } \\
\text { - } & \text { Quais as principais } \\
\text { estratégias para } \\
\text { formação dos } \\
\text { profissionais voltada } \\
\text { para atuação na APS? }\end{array}$ & $\begin{array}{l}\text { Interculturalidade } \\
\text { - Há programas } \\
\text { de formação dos } \\
\text { profissionais no campo } \\
\text { da diversidade cultural } \\
\text { ou áreas afins? } \\
\text { Há participação da } \\
\text { medicina indígena nos } \\
\text { programas de APS? }\end{array}$ \\
\hline
\end{tabular}

APS: atenção primária à saúde.

Fonte: Elaboração própria. 
A análise dos casos será apresentada a seguir e sintetizada por meio do Quadro 3 que caracteriza e confronta dimensões dos sistemas de saúde estudados, e do Quadro 4 que sumariza características da APS nos quatro casos. Ainda que entre os quatro países se observe consenso quanto à estruturação de reformas com foco no desenvolvimento de uma APS abrangente, cabe destacar que a consolidação da universalização e dessas reformas tem enfrentado desafios institucionais que perpassam várias das dimensóes de análise estudadas.

\section{Brasil}

A partir de 2003, o Brasil passou a ser governado por uma coalizáo de centro-esquerda, o que representou um marco de mudança nas elites governantes no país desde o final do regime militar em 1985 (ALMEIDA, 2004; TEIXEIRA; PAIM, 2005). A ascensão de Lula, após 15 anos de promulgação da Constituição Federal de 1988 e criação do Sistema Único de Saúde (SUS), sistema universal e público de saúde, gerou grandes expectativas em relação à implementação de mudanças para o avanço no processo de reforma sanitária no país.

Nesse momento, no que diz respeito à política nacional de APS, questionava-se como seria a conduçáo desta política específica e se esta permaneceria ocupando lugar de destaque no novo governo, visto que permanecera ao longo de toda a década de 1990 e início dos anos 2000 como prioritária na agenda federal (CASTRO; MACHADO, 2010), período em que ocorreram importantes transformações na atenção primária no país e foram estabelecidos os principais marcos da política em relaçáo à organização, financiamento e modelo de atenção da APS.

Vale destacar que no Brasil, nos anos 1990, optou-se pela utilização do termo atenção básica em referência ao conjunto de ações no primeiro nível de atenção. Diferentes estudos (FAUSTO, 2005; MELLO; FONTANELLA; DEMARZO, 2009) apontam que esta opção à época ocorreu em virtude da grande resistência que havia ao termo atenção primária, associado aos movimentos ocorridos na América Latina, pautados em uma visão focalizada, seletiva e imposta pelas agências multilaterais de financiamento. Atualmente, o próprio Ministério da Saúde utiliza os termos como sinônimos, embora a necessidade de distinção em um dado momento seja reconhecida por seus dirigentes (CASTRO, 2009).
Desde 1996, o Ministério da Saúde adotou o Programa Saúde da Família (PSF) como a estratégia prioritária para o fortalecimento das açóes de atenção básica no SUS e este passou a ser um objeto frequente das diretrizes normativas federais. Cabe mencionar que a origem do PSF está diretamente relacionada à formulação pelo Ministério da Saúde, em 1991, do Programa de Agentes Comunitários de Saúde (PACS). A criação do PACS representou a institucionalização de experiências locais de práticas com agentes comunitários que já vinham sendo desenvolvidas de forma isolada e focalizada em diversas regióes do Brasil (VIANA; DAL POZ, 1998). A ausência de consenso a respeito da efetividade desse programa, bem como a necessidade de romper com o modelo assistencial tradicional, foram fatores determinantes para a fusão do PACS ao PSF.

A institucionalização do PSF gerou diversas mudanças, que envolvem o modelo de atenção, a organização do sistema e as modalidades de alocação dos recursos - e fizeram com que este se constituísse, como apontam Viana e Dal Poz (1998), em uma estratégia de reforma incremental do sistema de saúde no Brasil. Machado (2006) destaca algumas características desta política que justificam sua permanência na agenda de prioridades do Ministério da Saúde, em diferentes gestôes ministeriais, com elevado grau de continuidade, na maior parte dos anos 1990, tais como o caráter inovador, o foco na família e comunidade, que a tornam um atraente marco de governo.

Assim como na década de 1990, ao término dos dois mandatos do governo Lula, foi possível observar que a política nacional de atenção primária permaneceu como política prioritária, cuja ênfase estava no PSF, que passou a ser denominado Estratégia Saúde da Família (ESF) (SAMPAIO, 2008). A cobertura populacional pela ESF é um dos indicativos do destaque conferido à APS no período, visto que esta passou de 35,7\% em 2003 para 52,2\% ao término de 2010 (isto é, de 16.700 equipes em 2002 para 31.700 equipes de saúde da família em 2010, um aumento de quase 100\%). Além disso, ocorreram algumas inovaçóes importantes, tais como a ampliação do escopo das açóes no âmbito da APS, ainda que antigas questôes não tivessem sido superadas.

Observa-se que algumas iniciativas adotadas no período de estudo lograram enfrentar fragilidades já 
Quadro 3. Caracterização dos sistemas públicos de saúde no Brasil, Bolívia, Venezuela e Uruguai

\begin{tabular}{|c|c|c|c|c|}
\hline Dimensões & Brasil & Bolívia & Venezuela & Uruguai \\
\hline Tipo de sistema & $\begin{array}{l}\text { Público Universal (artigos } \\
196 \text { a } 200 \text { da Constituição } \\
\text { Federal de 1988). } \\
\text { Cobertura universal, } \\
\text { definida na Constituição } \\
\text { Federal, Lei Orgânica e } \\
\text { normas complementares. } \\
\text { Modelo de vinculação } \\
\text { ao sistema baseado na } \\
\text { concepção de saúde como } \\
\text { direito de cidadania. }\end{array}$ & $\begin{array}{l}\text { Público Universal (artigo } \\
18 \text { da Constituição Política } \\
\text { do Estado de 2009). } \\
\text { Cobertura universal, } \\
\text { definida na Constituição } \\
\text { do Estado. Contudo, } \\
\text { persiste o sistema } \\
\text { anterior de seguros } \\
\text { diversificados de saúde } \\
\text { para grupos específicos } \\
\text { e para trabalhadores do } \\
\text { mercado formal. Somente } \\
\text { são cobertos pelo governo: } \\
\text { idosos, gestantes, crianças } \\
\text { até cinco anos e pessoas } \\
\text { com deficiência. } \\
\text { Modelo formal de } \\
\text { vinculação baseado } \\
\text { na saúde enquanto } \\
\text { direito de cidadania, em } \\
\text { contraste ao modelo } \\
\text { vigente (asseguramento } \\
\text { diversificado). }\end{array}$ & $\begin{array}{l}\text { Público Universal (artigo } 84 \\
\text { da Constituição de 1999). } \\
\text { Cobertura universal, } \\
\text { definida na Constituição. } \\
\text { Ausência de uma Lei } \\
\text { Orgânica da Saúde. } \\
\text { Apesar da constituição } \\
\text { do Sistema Público } \\
\text { Nacional de Saúde (SPNS) } \\
\text { (de caráter universal), } \\
\text { o modelo anterior } \\
\text { permanece vigente (por } \\
\text { meio da manutenção do } \\
\text { Instituto Venezuelano dos } \\
\text { Seguros Sociais), gerando } \\
\text { um sistema segmentado. } \\
\text { Pode-se afirmar que o } \\
\text { SPNS tem se desenvolvido } \\
\text { em torno do Programa } \\
\text { Misión Barrio Adentro } \\
\text { (MBA). }\end{array}$ & $\begin{array}{l}\text { Estado fornece assistência } \\
\text { gratuita apenas aos } \\
\text { indigentes e desprovidos } \\
\text { de recursos, conforme a } \\
\text { Constituição de } 1997 . \\
\text { Busca-se cobertura } \\
\text { universal progressiva, por } \\
\text { meio da incorporação } \\
\text { gradual de segmentos } \\
\text { populacionais a um } \\
\text { Seguro Nacional de Saúde } \\
\text { (FONASA) de acordo } \\
\text { com a Lei no } 18.211 \text { de } \\
\text { 2007, que cria o Sistema } \\
\text { Nacional Integrado de } \\
\text { Saúde (SNIS) e articula } \\
\text { seguros e prestadores } \\
\text { públicos e privados. } \\
\text { A saúde é compreendida } \\
\text { como um direito de todos, } \\
\text { contudo, o modelo formal } \\
\text { de vinculação ao sistema } \\
\text { está em parte associado à } \\
\text { condição laboral e o modo } \\
\text { de vinculação ocorre por } \\
\text { meio da afiliação a um } \\
\text { Seguro Nacional de Saúde. }\end{array}$ \\
\hline $\begin{array}{l}\text { Organização } \\
\text { do sistema: } \\
\text { prestação de } \\
\text { serviços e } \\
\text { integração entre } \\
\text { os níveis do } \\
\text { sistema }\end{array}$ & $\begin{array}{l}\text { Gestor municipal: } \\
\text { responsável pelos serviços } \\
\text { de atenção primária à } \\
\text { saúde (APS) e emergências. } \\
\text { Gestor estadual: } \\
\text { apoio financeiro e na } \\
\text { organização da APS nos } \\
\text { municípios; responsável } \\
\text { por serviços de média e } \\
\text { alta complexidade. } \\
\text { Gestor federal: não tem } \\
\text { funções na prestação. } \\
\text { Planeja e induz a política } \\
\text { nacional por meio de } \\
\text { incentivos financeiros. } \\
\text { O Sistema Único de Saúde } \\
\text { (SUS) prevê que a rede } \\
\text { assistencial se organize } \\
\text { por meio de regiões de } \\
\text { saúde. Os mecanismos } \\
\text { de coordenação entre } \\
\text { os níveis dependem de } \\
\text { processos de referência e } \\
\text { contra-referência. } \\
\text { Papel crescente do setor } \\
\text { privado na oferta de } \\
\text { serviços de saúde. }\end{array}$ & $\begin{array}{l}\text { Esfera municipal: } \\
\text { responsável pela } \\
\text { administração dos } \\
\text { estabelecimentos de } \\
\text { saúde por meio dos } \\
\text { Diretórios Locais de Saúde } \\
\text { (DILOS). } \\
\text { Esfera departamental: } \\
\text { operacionalizar as normas } \\
\text { emitidas pela esfera } \\
\text { nacional e responder as } \\
\text { necessidades de saúde } \\
\text { locais e regionais. } \\
\text { Esfera indígena: função } \\
\text { participativa e de decisão } \\
\text { em respeito à população } \\
\text { indígena da nação. } \\
\text { O seguro social atende aos } \\
\text { trabalhadores assalariados } \\
\text { do mercado formal. } \\
\text { O setor de medicina } \\
\text { tradicional corresponde } \\
\text { a rede básica de saúde e } \\
\text { serve aproximadamente } \\
\text { a } 10 \% \text { da população, } \\
\text { especialmente a rural. }\end{array}$ & $\begin{array}{l}\text { No marco do Plano } \\
\text { Nacional de Saúde, a } \\
\text { esfera nacional determina } \\
\text { e prioriza áreas de } \\
\text { intervenção em saúde; e } \\
\text { repassa recursos ao nível } \\
\text { estadual e a serviços, de } \\
\text { acordo com a necessidade } \\
\text { e critérios de pertinência } \\
\text { definidos nacionalmente. } \\
\text { A estrutura logística } \\
\text { pública é do Estado, } \\
\text { em todos os níveis de } \\
\text { complexidade do sistema. } \\
\text { As Misión Barrio Adentro I } \\
\text { (consultórios populares), } \\
\text { /I (diagnóstico), III e } \\
\text { IV (rede hospitalar) se } \\
\text { complementam para } \\
\text { a oferta de atenção } \\
\text { integral. Os mecanismos } \\
\text { de coordenação entre } \\
\text { os níveis dependem de } \\
\text { processos de referência e } \\
\text { contrarreferência. }\end{array}$ & $\begin{array}{l}\text { Prestadores integrais do } \\
\text { SNIS: a Administração } \\
\text { de Serviços de Saúde do } \\
\text { Estado (ASSE), principal } \\
\text { prestador público, as } \\
\text { Instituições de Assistência } \\
\text { Médica Coletiva (IAMC), } \\
\text { prestadores privados sem } \\
\text { fins lucrativos, além de } \\
\text { seguros privados com fins } \\
\text { lucrativos. } \\
\text { São estabelecidos } \\
\text { programas prioritários } \\
\text { de saúde para uma } \\
\text { atenção de qualidade } \\
\text { e a Junta Nacional de } \\
\text { Saúde (JUNASA) } \\
\text { define os benefícios } \\
\text { ofertados e controla a } \\
\text { sua execução por esses } \\
\text { prestadores. A JUNASA } \\
\text { também atua sobre os } \\
\text { mecanismos de referência } \\
\text { e contrarreferência entre } \\
\text { os níveis de atenção } \\
\text { e estabelece política } \\
\text { de coordenação entre } \\
\text { serviços públicos e } \\
\text { privados. }\end{array}$ \\
\hline
\end{tabular}


Quadro 3. Continuação

\begin{tabular}{|c|c|c|c|c|}
\hline Dimensões & Brasil & Bolívia & Venezuela & Uruguai \\
\hline Financiamento* & $\begin{array}{l}\text { Por meio de recursos do } \\
\text { orçamento da seguridade } \\
\text { social, da União, dos } \\
\text { Estados, do Distrito Federal } \\
\text { e dos Municípios, além de } \\
\text { outras fontes (art. } 198 \text { da } \\
\text { CF 1988). } \\
\text { Formalmente, o setor } \\
\text { privado deveria atuar } \\
\text { em caráter suplementar, } \\
\text { contudo, o percentual de } \\
\text { gasto privado no gasto } \\
\text { total em saúde foi de } \\
54,3 \% \text { em } 2009 \text {. } \\
\text { Não há copagamento no } \\
\text { sistema público. }\end{array}$ & $\begin{array}{l}\text { Por meio de recursos } \\
\text { externos, do Tesouro } \\
\text { Nacional e municípios. } \\
\text { Proposta de aumento } \\
\text { do percentual dos } \\
\text { municípios, e do Tesouro } \\
\text { Nacional, bem como } \\
\text { o estabelecimento } \\
\text { de percentual para a } \\
\text { saúde no imposto sobre } \\
\text { hidrocarbonetos. } \\
\text { O gasto público em saúde } \\
\text { como percentual do gasto } \\
\text { total em saúde foi de } \\
65,1 \% \text { em } 2009 . \\
\text { Copagamento: a } \\
\text { população não segurada } \\
\text { nas formas de seguro } \\
\text { público existentes } \\
\text { paga pelos serviços de } \\
\text { saúde utilizados nos } \\
\text { estabelecimentos públicos. }\end{array}$ & $\begin{array}{l}\text { Principalmente, por meio } \\
\text { de recursos do Orçamento } \\
\text { Público Nacional; havendo } \\
\text { recursos complementares } \\
\text { do nível estadual e } \\
\text { municipal e do Seguro } \\
\text { Social. } \\
\text { O gasto público em saúde } \\
\text { como percentual do gasto } \\
\text { total em saúde foi de } 40 \% \\
\text { em } 2009 \text {. } \\
\text { A prestação de } \\
\text { serviços de saúde nos } \\
\text { estabelecimentos } \\
\text { públicos é gratuita e sem } \\
\text { copagamentos. }\end{array}$ & $\begin{array}{l}\text { Por meio de recursos do } \\
\text { governo, das empresas } \\
\text { e dos empregados, que } \\
\text { compõem o Fundo } \\
\text { Nacional de Saúde } \\
\text { (FONASA), administrado } \\
\text { pela JUNASA. } \\
\text { O gasto público em saúde } \\
\text { como percentual do gasto } \\
\text { total em saúde foi de } \\
\text { 63,1\% em } 2009 \text {. } \\
\text { Existe copagamento } \\
\text { nas IAMC, mas a atual } \\
\text { política de regulação } \\
\text { prevê o fim ou a redução } \\
\text { do mesmo para alguns } \\
\text { grupos e programas. } \\
\text { Não há copagamentos } \\
\text { nos serviços da ASSE } \\
\text { (públicos). }\end{array}$ \\
\hline Regulação & $\begin{array}{l}\text { Regulação do sistema } \\
\text { e de serviços de saúde } \\
\text { é competência das três } \\
\text { esferas de governo. } \\
\text { Espaços formais de } \\
\text { regulação e gestão } \\
\text { compartilhada: Comissão } \\
\text { Intergestores Tripartite, } \\
\text { Bipartite e Regionais (CIT, } \\
\text { CIB e CIR). } \\
\text { Regulação sanitária } \\
\text { exercida pela Agência } \\
\text { Nacional de Vigilância } \\
\text { Sanitária (ANVISA) em nível } \\
\text { federal. Também exercida } \\
\text { complementarmente } \\
\text { pelos estados. } \\
\text { Regulação de mercados } \\
\text { em saúde realizada pela } \\
\text { Agência Nacional de } \\
\text { Saúde Suplementar (ANS) } \\
\text { em nível federal. }\end{array}$ & $\begin{array}{l}\text { Regulação é } \\
\text { responsabilidade do } \\
\text { Ministério da Saúde (MS), } \\
\text { que é o reitor do Sistema } \\
\text { Único de Saúde. } \\
\text { Regulação sanitária } \\
\text { exercida por } \\
\text { departamentos do } \\
\text { MS como a Unidad de } \\
\text { Medicamentos y Tecnología } \\
\text { en Salud que regula o } \\
\text { mercado farmacêutico. }\end{array}$ & $\begin{array}{l}\text { Regulação é } \\
\text { responsabilidade do } \\
\text { Ministério do Poder } \\
\text { Popular para a Saúde } \\
\text { (MPPS). } \\
\text { O MPPS é o reitor do SPNS, } \\
\text { responsável por garantir a } \\
\text { integração das instituições } \\
\text { prestadoras de serviços e } \\
\text { outros serviços públicos } \\
\text { em uma rede organizada } \\
\text { por níveis, sendo a porta } \\
\text { de entrada ao sistema o } \\
\text { primeiro nível de atenção } \\
\text { das unidades do Misión } \\
\text { Barrio Adentro I. } \\
\text { Regulação sanitária } \\
\text { exercida pelo Servicio } \\
\text { Autónomo de Contraloría } \\
\text { Sanitaria (SACS), um } \\
\text { serviço com autonomia } \\
\text { orçamentária subordinado } \\
\text { ao MPPS em conjunto com } \\
\text { outros departamentos do } \\
\text { Ministério da Saúde. }\end{array}$ & $\begin{array}{l}\text { No âmbito da regulação de } \\
\text { serviços, cabe à JUNASA, } \\
\text { órgão descentralizado } \\
\text { do Ministério de Saúde } \\
\text { Pública, administrar o } \\
\text { Seguro Nacional de Saúde } \\
\text { e monitorar os prestadores } \\
\text { integrais do SNIS, com os } \\
\text { quais são estabelecidos } \\
\text { contratos de gestão. } \\
\text { Regulação sanitária } \\
\text { exercida pelo Ministério } \\
\text { de Saúde Pública (MSP) } \\
\text { compartilhada pela } \\
\text { Divisão de Epidemiologia } \\
\text { e a Divisão de Avaliação } \\
\text { Sanitária. }\end{array}$ \\
\hline
\end{tabular}

Fonte: Elaboração própria a partir de: BRASIL, 1988; 1990; BOLIIVIA, 2011; LEDO; SORIA, 2011; BONVECCHIO; BECERRIL; CARRIEDO, 2011; SOLLAZZO; BERTERRETCHE, 2011; RED, 2009/2010; ISAGS, 2011.

*Os dados relativos aos percentuais de gasto em saúde foram extraídos de WHO (2012). 


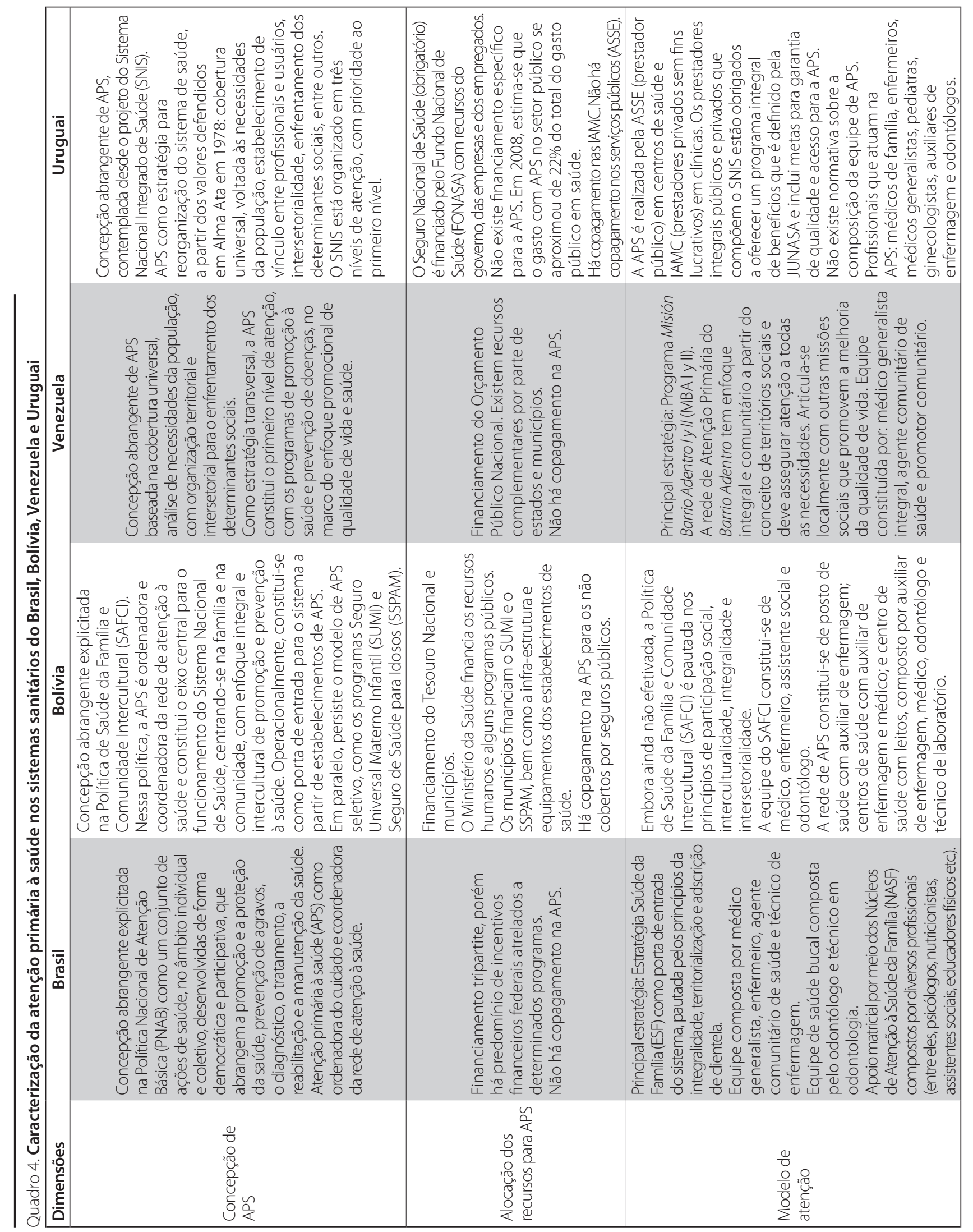




\begin{tabular}{|c|c|c|c|}
\hline 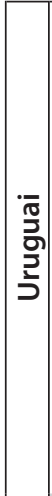 & 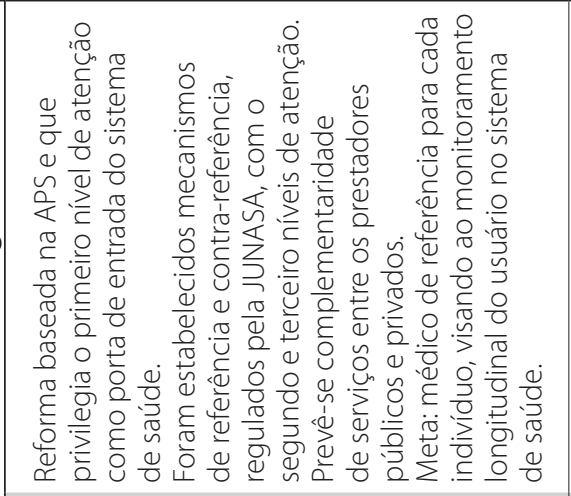 & 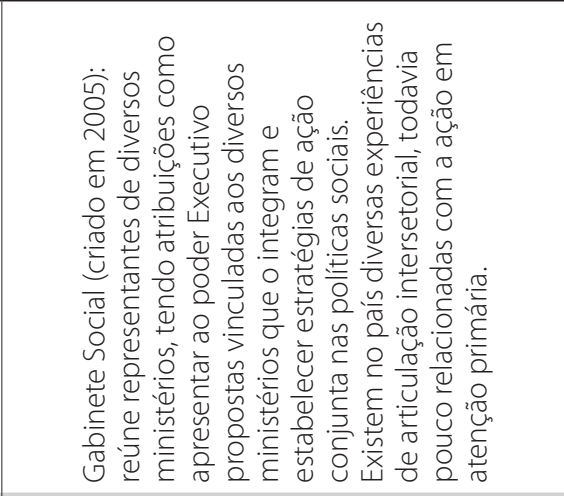 & 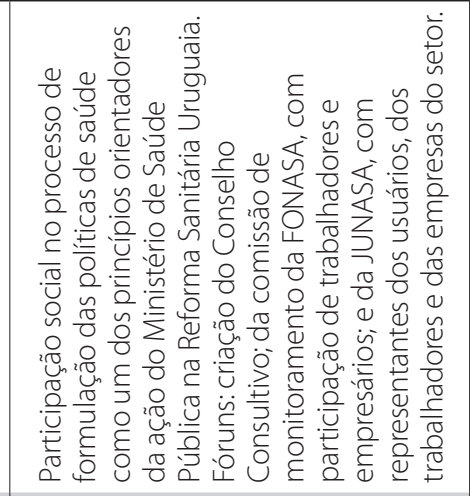 \\
\hline 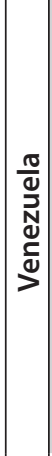 & 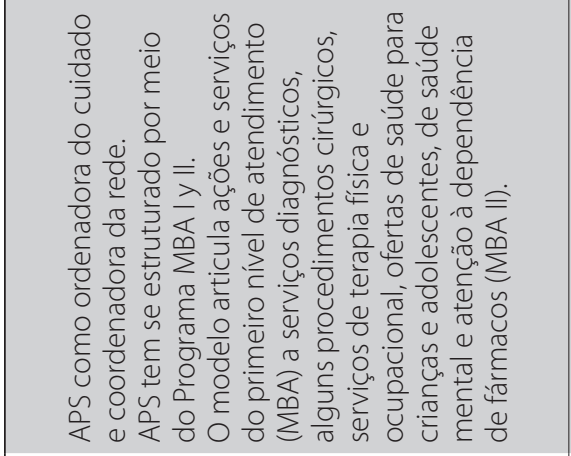 & 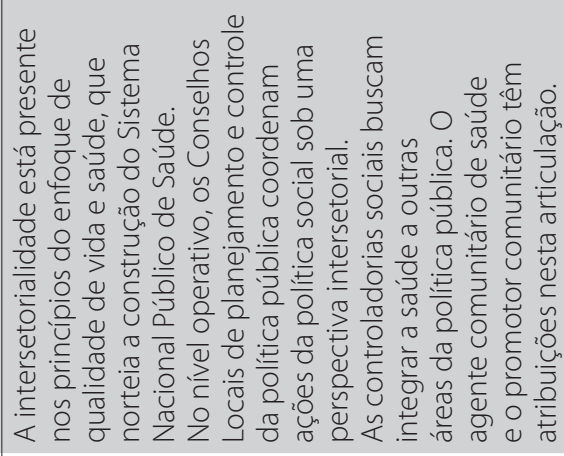 & 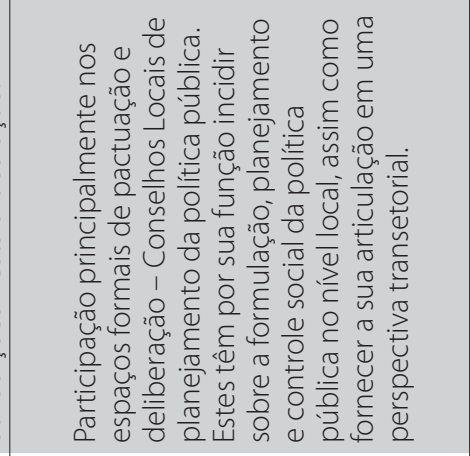 \\
\hline & 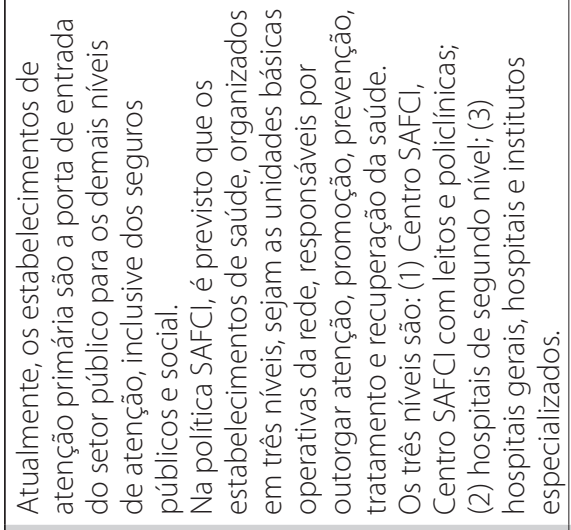 & 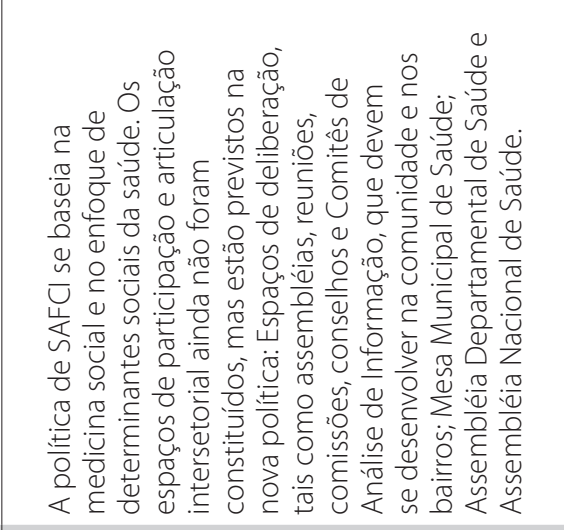 & 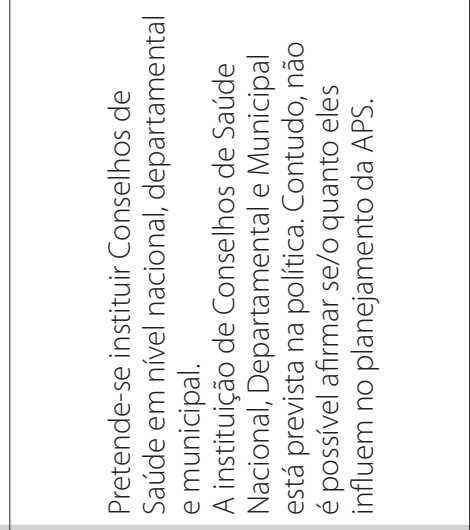 \\
\hline & 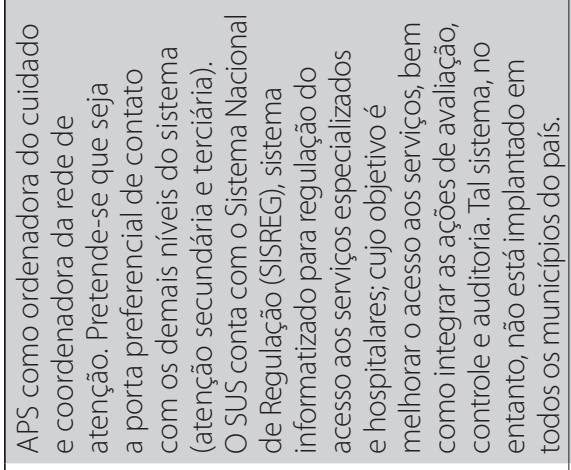 & 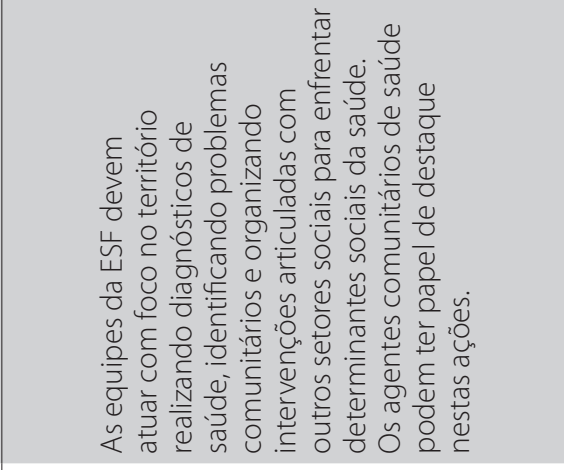 & 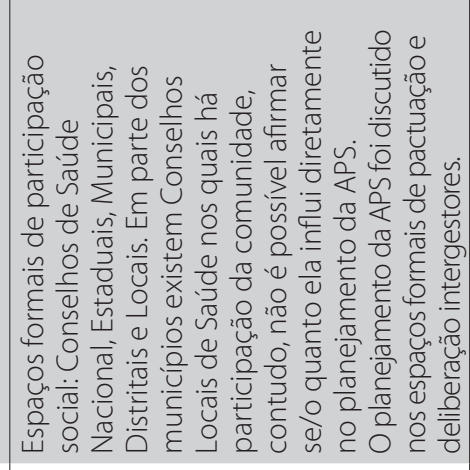 \\
\hline 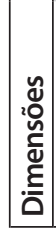 & 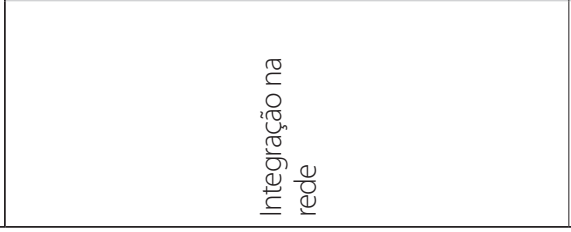 & 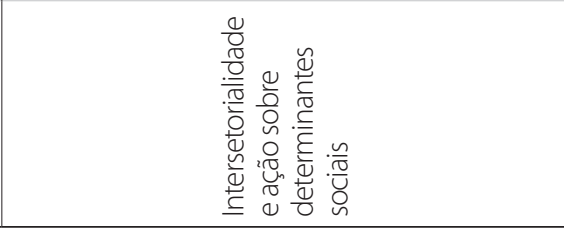 & 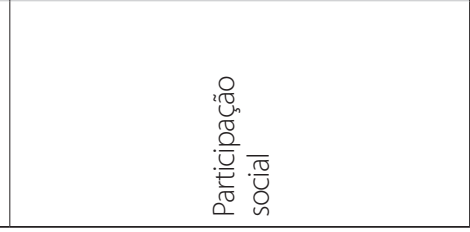 \\
\hline
\end{tabular}




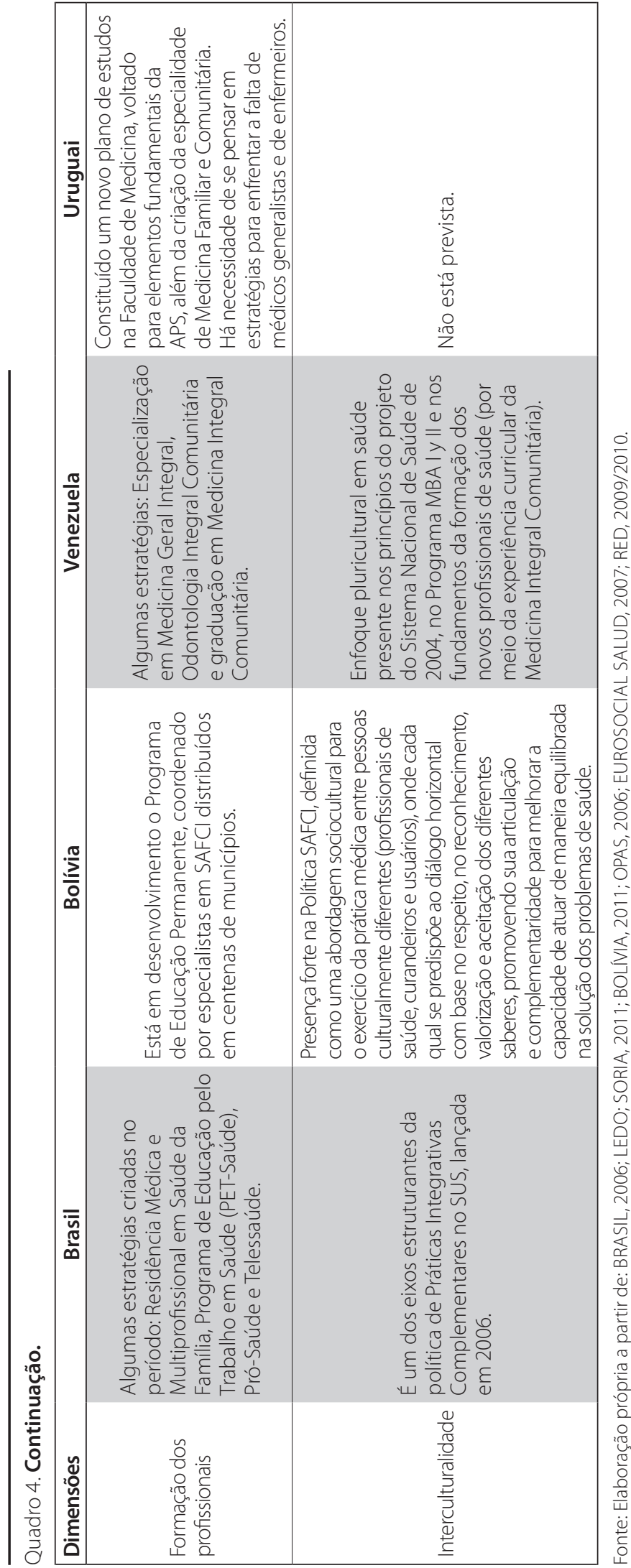

identificadas com relação à atenção primária à saúde no país. Nesse sentido, foram estratégias prioritárias a expansáo da ESF para os grandes centros, por meio do programa PROESF, a ampliaçáo das açóes na atenção básica, a incorporação de novos profissionais à Estratégia - por meio da criação dos Núcleos de Apoio ao Saúde da Família (NASF) — e a criação de programas voltados para a mudança na formação de recursos humanos e educação permanente, tais como PETSaúde e o Pró-Saúde.

Outra estratégia importante que ganhou destaque no período foi a Política Nacional de Saúde Bucal. Ainda que no governo anterior tivessem sido tomadas as primeiras iniciativas com intuito de enfrentar o desafio de melhorar a atenção odontológica no SUS e reverter os péssimos indicadores de saúde bucal da população brasileira, foi no período de 2003 a 2010 que a Política Nacional de Saúde Bucal obteve lugar de destaque e novos contornos, ampliando sua abrangência e conferindo-lhe caráter inovador. Isso se expressa, por exemplo, no crescimento do número de equipes de saúde bucal, que em 2003 eram 6.170 e passam para 20.424 em 2010.

No que diz respeito ao financiamento federal da atenção básica, permanece a fragmentação, com criação de diversos novos incentivos financeiros atrelados à adesão de programas por estados e municípios. Ainda que os recursos destinados à atenção básica fossem insuficientes (CASTRO; MACHADO, 2010), observou-se o esforço do gestor federal em garantir um aporte maior de recursos para esta política. Além disso, pela primeira vez foram empregados indicadores de condiçóes sociais como critério para diferenciar os repasses federais aos municípios para financiamento do SUS. A utilização destes indicadores está associada à busca da equidade, uma das atribuiçóes do gestor federal na implementação de um sistema nacional de saúde em um país federativo e táo desigual como o Brasil.

No que diz respeito à participação social no processo de formulação da política de atenção básica no âmbito nacional, é possível afirmar que, embora bastante complexa, ela foi amplamente compartilhada com os diferentes atores que influenciam a configuração dessa política. A participaçáo ocorreu principalmente nos espaços formais de pactuação e deliberação, com destaque 
para Comissão Intergestores Tripartite e o Conselho Nacional de Saúde, o que representa um avanço para a consolidação do SUS.

Embora a APS tenha ocupado lugar central na nova agenda federal, em uma perspectiva abrangente, ainda há numerosos desafios a serem enfrentados. Dentre estes, destaca-se a formação de redes regionalizadas e a superação do modelo fragmentado e segmentado de atenção à saúde, em que a participação do setor privado é bastante significativa e caracterizada pela oferta de serviços altamente diversificados e especializados. Vale mencionar que a permanência deste modelo é em parte favorecida pela existência de subsídios públicos à saúde privada. Além disso, aumentar a resolutividade da APS é uma questão importante para a consolidação deste nível de atenção como porta de entrada preferencial do sistema e serviço de procura regular, como defendido pela política nacional.

O enfrentamento desses desafios é fundamental para que ocorra a consolidação da atenção primária à saúde no país como estratégia estruturante do SUS, principalmente no que se refere à efetivação de seu papel como ordenadora do cuidado e coordenadora da Rede de Atenção à Saúde.

\section{Bolívia}

A vitória do partido socialista na Bolívia reacendeu a esperança de interrupçáo do processo de reformas neoliberais que marcaram o país por mais de 15 anos. Eleito em 2006, Evo Morales, liderança indígena do partido Movimiento al Socialismo, iniciou açóes transformadoras em diversas dimensóes.

No âmbito da saúde, a nova presidência defrontou-se com um sistema de saúde fragmentado, de qualidade questionável e com acesso limitado da população aos serviços, com reflexos sobre os indicadores de saúde (SILVA et al., 2009). No entanto, ainda em 2006, o Ministério da Saúde apresentou um plano para redesenhar a política de saúde do país, revelando vontade política e ideias inovadoras (SILVA et al., 2009).

Em 2008, o Decreto Supremo no 29.601 estabeleceu como modelo de atenção e gestão da saúde no país a Saúde Familiar Comunitária Intercultural (SAFCI). Tal modelo objetiva contribuir para o acesso efetivo aos serviços de saúde abrangentes; fortalecer e aprofundar a participação social efetiva na tomada de decisóes e na gestão compartilhada da prestação de serviços de saúde que levem em conta o indivíduo, a família e a comunidade; e aceitar, respeitar, apreciar e articular a medicina biomédica com a medicina dos povos indígenas e camponeses, contribuindo para a melhoria das condiçóes de vida da população (BOLÍVIA, 2011). Cabe destacar que a APS foi implementada na Bolívia, inicialmente, na década de 1980, como um dos pacotes das reformas neoliberais, baseado no modelo seletivo, pautado em programas focalizados que persistem até os dias atuais no país. Atualmente, a denominação APS não é utilizada, distanciando-se da política anterior, e tem sido tratada nos termos da Saúde Familiar Comunitária Intercultural e da Gestão Compartilhada da Saúde (BOLÍVIA, 2011).

Em 2009, o governo deu continuidade às tentativas de mudanças na política de saúde e instituiu por meio da nova Constituição Política do Estado Plurinacional da Bolívia, o SUS, que deveria ser não só universal, mas equitativo, gratuito, participativo, intra e intercultural, com qualidade, eficácia e controle social. A Carta Magna não aborda diretamente a APS, mas estabelece que o Estado deva priorizar açóes de promoção e prevenção de doenças e fomentar a participação popular na gestão e na tomada de decisóes no sistema público de saúde (BOLÍVIA, 2009).

As principais açóes pretendidas para o modelo de atenção primária boliviano envolvem a promoção, prevenção e educação em saúde, consultas ambulatoriais, internação para observação (nos estabelecimentos com leitos) e visitas domiciliares (BOLÍVIA, 2011) (Quadro 4). Dentre seus objetivos prioritários, está a participaçáo social, com intuito de diminuir as barreiras culturais de acesso aos serviços de saúde e estimular a participação dos povos indígenas. Para isto, pretende-se instituir conselhos de saúde a nível nacional, departamental e municipal.

O sistema de saúde boliviano é segmentado e apresenta quatro setores: o sistema público; o de seguridade social; o privado; e o de medicina tradicional (Quadro 3). Além do seguro social para os trabalhadores do setor formal, existem seguros focalizados em programas públicos voltados para populaçóes específicas, como o Seguro Universal Materno Infantil (SUMI), para mães 
e crianças menores de 5 anos; o Seguro de Saúde para Idosos (SSPAM), para maiores de 60 anos; e o Programa Multissetorial de Desnutrição Zero, cujo objetivo é erradicar a desnutrição aguda e crônica em crianças menores de 5 anos. Já as unidades de saúde se encontram organizadas em redes, classificadas como: Redes Municipais de Saúde, compostas por unidades de atenção primária e hospitais de segundo nível; e Redes Departamentais da Saúde que incluem várias redes municipais e o terceiro nível de atenção (LEDO; SORIA, 2011).

A política de Saúde Familiar Comunitária Intercultural se baseia na medicina social e no enfoque de determinantes sociais da saúde. A APS na Bolívia está voltada para a população que possui algum seguro público, sendo constituída por diferentes instalaçóes físicas tais como Postos de Saúde, Centros de Saúde e Centro de Saúde com leitos. Cabe reiterar que a população não beneficiária dos seguros públicos realiza desembolso direto pelos serviços que recebem nesses estabelecimentos, que estão a cargo dos municípios. Prevê-se abolir estes copagamentos em 2012 (BOLÍVIA, 2011).

O sistema público é financiado por recursos tanto do Tesouro Nacional quanto de financiadores e doadores externos. O Tesouro Nacional, maior financiador público, é o responsável pelo pagamento dos profissionais da saúde e pelos programas nacionais de saúde. Os municípios financiam o SUMI e SSPAM e, além disso, são responsáveis pela infraestrutura e equipamentos dos estabelecimentos públicos de saúde. Já os recursos externos destinam-se principalmente para investimentos em saúde (BOLÍVIA, 2011; LEDO; SORIA, 2011).

No que diz respeito aos recursos humanos, o Ministério da Saúde e Esportes reconhece uma má distribuição e escassez de profissionais de saúde, principalmente médicos na zona rural (BOLÍVIA, 2011). A inexistência de uma política de recursos humanos associada à predominância do setor privado na formação resulta na falta de profissionais para responder às necessidades da nova proposta do SUS. Na avaliação do Ministério da Saúde e do Desporto, na atualidade, os profissionais são formados sob a lógica mercantilista, sem estímulo à solidariedade e ao trabalho em equipe, modelo oposto ao que o país está propondo (BOLÍVIA, 2011). A única experiência prática da Estratégia de Saúde Familiar Comunitária Intercultural é através da
Residência Médica nessa especialidade e com as Equipes Móveis SAFCI. Tal experiência ainda é restrita a alguns municípios (BOLÍVIA, 2011).

Em síntese, ainda que esforços tenham sido feitos no sentido de reformar o sistema de saúde boliviano como a implantação de um modelo assistencial integral com a Saúde Familiar Comunitária Intercultural, persiste um sistema de saúde segmentado com predomínio do modelo de APS seletiva. A segmentação entre diferentes tipos de seguros e coberturas, bem como a fragmentação das redes constituem importantes problemas do sistema, produzindo profundas iniquidades no acesso aos serviços de saúde, permanecendo elevados níveis de exclusão.

\section{Venezuela}

A ascensão de Hugo Chaves à presidência em 1999 significou a queda do antigo regime político e implementação de reformas estruturais do Estado e suas instituiçôes, na tentativa de contrapor às tendências neoliberais dos anos 1990. Tais reformas ocorreram em um contexto de polarização política e social, bem como de instabilidade institucional.

A nova Constituição, finalmente acordada em 1999, reconheceu a saúde como um direito social a cargo do Estado, e estabeleceu a obrigatoriedade da criação do SPNS, como um subsistema do Sistema de Proteção Social com caráter intersetorial, descentralizado e participativo (VENEZUELA, 1999). Porém, até o presente momento, a Venezuela não conta com uma lei orgânica da saúde que possa harmonizar as estruturas institucionais prévias a 1998 e as iniciativas governamentais atuais, tais como o Programa Misión Barrio Adentro I y II (MBA I y II), e estas, com as mudanças previstas na nova carta constitucional.

Com o advento do governo Chaves e a nova Constituiçấo, a reforma em saúde parece ter seguido dois caminhos. $\mathrm{O}$ primeiro pode ser considerado como a via formal, e até certo ponto apenas discursiva, que no fraco plano de regulamentaçáo concebe a organização do SPNS a partir do desenvolvimento do nível local por meio da estratégia de APS abrangente, de forma articulada aos instrumentos de planejamento e controle social. O segundo está relacionado ao imperativo fático, ou seja, ao que foi possível diante da 
realidade marcada pela crise gerada pela greve patronal e pela tentativa de golpe de Estado em 2002, com todas as suas negativas consequências para a estabilidade institucional do país, para sua economia e das próprias famílias (RODRÍGUEZ, 2010). Por meio da reforma, pretendeu-se mudar o sistema de saúde como um todo.

AAPS teve destaque na política de saúde com desenvolvimento do Programa MBA I y II (Quadros 3 e 4). A Misión Barrio Adentro (MBA) desenvolve uma estratégia estatal inscrita a territórios e ligada aos sistemas de participação social na esfera do planejamento e fiscalização transetorial da política pública no nível local, estabelecida pela Constituição Política do país. A MBA inscreve-se no movimento da APS abrangente, integrada a outras 'missóes sociais' que procuram garantir a inclusão social e o exercício efetivo de direitos sociais para toda a população. Com enfoque comunitário e a expansão de uma estrutura de consultórios chamados de 'populares', que servem igualmente como habitação aos profissionais de saúde, as equipes desenvolvem ações de atenção médica e odontológica, de prevenção da doença e promoção da saúde, o que constitui o primeiro nível de atenção (MBA I). Com mecanismos de coordenação da rede de serviços, esta estratégia é complementada com um segundo nível de atenção (MBA II), conformado pelos Centros de Diagnóstico Integral que procuram fornecer o diagnóstico precoce - incluem endoscopia, oncologia, citologia, laboratório clínico, eletrocardiografia, oftalmologia, urgências, raio-X, ultrassom e alguns procedimentos cirúrgicos; as salas de reabilitação integral, com capacidade para ofertar serviços de terapia física e ocupacional; este nível é complementado pelas clínicas populares e ambulatórios de especialidades com ofertas de saúde para crianças e adolescentes, de saúde mental e atenção a dependentes de fármacos.

Ainda que se incorpore nos territórios uma estratégia de formação de pessoal de saúde ao nível de especialidade com programas de Medicina Geral Integral, Odontologia Integral Comunitária e a formação de graduados em Medicina Integral Comunitária, uma grande parte do Programa ainda é desenvolvida por médicos cubanos.

Apesar dos problemas relativos às difíceis condiçóes derivadas das mudanças sociopolíticas e sociais e institucionais no setor saúde, a MBA mostra uma expansão significativa da infraestrutura e incremento de $97 \%$ no número de consultas realizadas entre 2003-2007 (MPPS, 2008). Além disso, os índices de mortalidade materna, baixo peso ao nascer e mortalidade em menores de cinco anos, mais direitamente relacionados com a APS, mostram algumas melhorias, todavia, ainda não muito significativas se comparadas a 2003 (GONZÁLEZ, 2005).

Mas estes resultados relativamente positivos podem ser afetados por problemas estruturais derivados da organização do Sistema de Saúde. Na prática, podem-se identificar três estratos populacionais que são atendidos por subsistemas diferentes: 1) A população marginalizada e mais pobre, urbana e rural, é atendida principalmente pela MBA; 2) A população do setor formal da economia é atendida pelo Instituto Venezuelano da Seguridade Social (IVSS); neste mesmo estrato, as forças armadas, o setor educativo e universidades participam com caixas próprias. Neste caso, a fonte de recursos são as cotizaçóes dos mesmos trabalhadores, os empregadores e o governo, com taxas diferenciadas estabelecidas pela lei de seguro social; 3) A população com mais alta renda utiliza seguros privados.

Com a ausência da lei orgânica da saúde, os processos de adequação aos novos princípios valorativos e operativos têm sido lentos, difíceis e algumas vezes até contraditórios (GONZÁLEZ, 2005; BONVECCHIO; BECERRIL; CARRIEDO, 2011). Este fato dificulta a harmonização dos processos de integração funcional, de direção e de governança do setor; mas, além disso, limita a integração aos outros subsistemas do seguro social, assim como deste, com as outras instituiçóes dos poderes do Estado. Os mecanismos de avaliaçáo, de planejamento, controle e os critérios de alocação de recursos da MBA seguem sendo assuntos críticos e parte de uma agenda a se considerar (BONVECCHIO; BECERRIL; CARRIEDO, 2011).

\section{Uruguai}

O processo de reforma sanitária no Uruguai teve início com as eleiçóes presidenciais em 2004, quando uma coalizão de esquerda foi eleita. Novas leis e decretos introduziram as principais mudanças no sistema, voltadas para os modelos de atenção, de financiamento e de gestáo. Nesse contexto, destaca-se a Lei $\mathrm{n}^{\circ} 18.211$ de dezembro de 2007, que cria o SNIS e apresenta a proteção à saúde como um direito de todos os residentes do país (SOLLAZZO; BERTERRETCHE, 2011). 
O SNIS está pautado nos princípios de cobertura universal, equidade, continuidade do cuidado de forma oportuna, integralidade, qualidade da atenção e respeito aos direitos dos usuários. As responsabilidades do Estado foram expandidas, de modo que o Ministério de Saúde Pública assumiu funções como elaborar, organizar e controlar o funcionamento do sistema, registrar e habilitar os prestadores de serviços de saúde, além de fiscalizar sua articulação no sistema (ISAGS, 2011).

O país segue o processo recente de renovação da APS nas Américas, tendo esta como estratégia para reorganização do sistema. $\mathrm{O}$ novo modelo de atenção privilegia o primeiro nível de atenção, que é porta de entrada do sistema, e sua integração com os níveis secundário e terciário, por meio de mecanismos de referência e contrarreferência, na construção de uma atenção integral à população (EUROSOCIAL SALUD, 2007).

Os prestadores integrais do SNIS, responsáveis pela oferta de serviços à população coberta pelo Seguro Nacional de Saúde, são: a Administração de Serviços de Saúde do Estado (ASSE), principal prestador público com cobertura nacional; as Instituições de Assistência Médica Coletiva (IAMC), mútuas ou cooperativas privadas sem fins lucrativos; e os seguros privados integrais com fins de lucro. Além desses, existem diversos prestadores públicos e privados que oferecem níveis diversos de integralidade na assistência, como os hospitais universitário, policial e militar e os planos odontológicos e cirúrgicos, respectivamente. Estão previstas etapas de incorporação de segmentos populacionais ao seguro nacional, que deve cobrir $71 \%$ da população em 2016 (ISAGS, 2011).

Os mecanismos de financiamento do sistema foram redefinidos com a criação do Seguro Nacional de Saúde, que funciona como um seguro social (vinculado à condição laboral), ao qual está associado o Fundo Nacional de Saúde (FONASA) que recebe recursos do Estado, das empresas e dos empregados e é administrado pela Junta Nacional de Saúde (JUNASA), órgão do Ministério de Saúde Pública. Para a cobertura de atividades de baixa prevalência que requerem tecnologia de alto custo, existe o Fundo Nacional de Recursos, que cobre procedimentos como cateterismo cardíaco, angioplastia, diálise, entre outros. Não está previsto um financiamento específico para a APS (ISAGS, 2011).
Na gestão do sistema, a JUNASA tem papel fundamental, pois estabelece contratos de gestão com os prestadores integrais, públicos e privados, que são obrigados a oferecer um programa integral de benefícios aos usuários. Os prestadores são pagos através de transferências com base em um valor per capita, a 'cuota salud, ajustado por risco (sexo, idade) e por cumprimento de metas assistenciais, através de incentivos vinculados a programas da APS. Cabe à JUNASA acompanhar a execução desses programas, que são definidos pelo Ministério de Saúde Pública, além de fazer a coordenação entre os prestadores, de modo que os serviços públicos e privados funcionem de maneira complementar (Red, 2009/2010).

Algumas dificuldades podem ser observadas para concretização da APS no Uruguai, de modo a ser percebida uma prática ainda distante da teoria de acordo com Sollazzo e Berterretche (2011). Mesmo sendo a estratégia de reorientação do sistema, os recursos destinados a APS ainda são considerados insuficientes. Quanto à formação dos profissionais, observa-se uma queda na formação de médicos generalistas e de profissionais de enfermagem, mas novos esforços têm sido realizados, como a construção de um novo currículo e a criaçáo da especialidade medicina familiar e comunitária. Não existe normativa sobre quais profissionais devem fazer parte da equipe de APS, mas parece haver consenso quanto à participação do médico de família e do enfermeiro (SOLLAZZO; BERTERRETCHE, 2011).

A cesta de serviços ofertada na APS é considerada inadequada e diferenças são notadas segundo o local e o meio (urbano ou rural), de modo que a regionalização é um processo considerado fundamental para coordenação dos serviços. A integração vertical, entre os níveis de atenção, apresenta dificuldades, de acordo com a região, se na capital ou no interior, e com a atuação dos gestores. Quando existem, os mecanismos de referência e contrarreferência são considerados insatisfatórios (SOLLAZZO; BERTERRETCHE, 2011).

\section{DISCUSSÃO}

O chamado 'relançamento' da APS, impulsionado pela Organização Mundial da Saúde e pela Organização 
Pan-americana da Saúde, no contexto da América do Sul, buscou resgatar os referências de Alma Ata como parte de um processo de reposicionamento frente às consequências sociais dos ajustes macroeconômicos no contexto de liberalização dos anos 1990. Nesse sentido, Silva et al. (2009, p. 274) afirmam que:

\section{En la primera década del siglo XXI, los paises latinoamericanos continúan distanciándose de los modelos neoliberales y están jugando un pa- pel activo en el revivir la Atención Primaria Integral en Salud.}

O deterioramento dos indicadores de saúde, o aumento das iniquidades e o crescimento da pobreza, assim como a crise originada no desgaste dos sistemas políticos de cunho neoliberal, foram fatores essenciais para recolocar na agenda pública dos países estudados a discussão sobre APS.

Os casos estudados apontam para mudanças na estrutura dos sistemas de saúde em direção à universalização e evidenciam como tendência a necessidade de se avançar para uma 'APS abrangente de fato'. Ou seja, compreender a APS como o principal eixo de organização dos sistemas de saúde, dada sua importância na possibilidade de desenvolver modelos de atençâo integral baseados na promoçáo da saúde e a prevenção da doença, voltados para a intersetorialidade e para o reconhecimento das comunidades como atores políticos dentro do sistema, com açóes definidas no campo do planejamento e controle sobre os serviços. Nesse sentido, é preciso destacar que o curso específico tomado nos diferentes países está fortemente determinado tanto pelas condiçóes históricas da organização em saúde, as características das instituiçóes a serem reformadas, seus sistemas políticos e administrativos, assim como pelos contextos sociopolíticos em que ocorreram tais reformas.

O processo de reestruturação da APS, no Brasil, aproxima-se de uma concepção de APS abrangente, visto que define a APS como ordenadora do cuidado e coordenadora da rede de atenção, em uma perspectiva integrada à rede, preocupando-se com o estabelecimento de vínculo entre população e profissionais de saúde, com a intersetorialidade e a participação comunitária.
Contudo, enfrenta desafios impostos pela estrutura federativa do país e pelas grandes iniquidades regionais, além de um importante crescimento do setor privado, que náo contribui com os esforços públicos de organizar a APS como o eixo nuclear do sistema de saúde como um todo. Conill, Fausto e Giovanella (2010) ressaltam que apesar dos efeitos positivos promovidos pela ampliação da cobertura da ESF, a fragilidade do processo de regionalização dos serviços e dos mecanismos de referência entre níveis de atenção têm comprometido a integralidade no SUS.

As características da renovação da APS no caso da Venezuela revelam um processo complexo condicionado pela polarizaçáo política e social do país. Ainda assim, cabe destacar o movimento em direção à concepção de APS abrangente por meio do Programa MBA, que se pauta na perspectiva de APS integrada à rede, visando ao fortalecimento das ações de promoção e prevenção da saúde. Além dos condicionantes sociopolíticos, a reforma orientada pela APS é diretamente atingida pela instabilidade institucional do setor saúde, marcado por uma regulação estatal frágil, forte centralismo na gestão pública e o enfrentamento entre o Estado e as diferentes categorias de profissionais da saúde, com destaque para o embate com o contingente considerável de médicos cubanos que assumiram postos de atendimento no Programa MBA.

O caso do Uruguai sugere avanços no que diz respeito à institucionalização de um sistema sanitário pautado na concepção de universalidade e de APS abrangente como estratégia reordenadora, contudo, frente à diversidade de prestadores este alcance parece ser incipiente, situando-se assim como em parte na experiência brasileira no primeiro nível de atenção. A reforma baseada na APS privilegia o primeiro nível de atenção como porta de entrada do sistema de saúde, tendo sido estabelecidos mecanismos de referência e contrarreferência com os demais níveis de atenção. Apesar de alguns instrumentos que contribuem para a operacionalização da APS no campo do planejamento e gestão, ainda existem dificuldades para sua concretização, que envolvem, sobretudo, a consolidação da universalidade no acesso ao sistema, além do desenvolvimento de uma política de formação de recursos humanos adequada as suas necessidades e da integração assistencial. 
No caso da Bolívia, o contexto social com forte presença indígena, de ruralidade extensa e histórica exclusão, levou a um enfrentamento com a elite política tradicional, situaçáo que condicionou o desenvolvimento da APS. Buscando superar a história de uma APS segmentada e restrita, a Bolívia voltou-se para o desenvolvimento de uma APS abrangente, com destaque para organização dos serviços sob enfoque intercultural. Percebe-se que a Bolívia enfrenta dificuldades importantes para pôr em prática as políticas propostas, com destaque para a permanência de seguros públicos seletivos por grupo populacional, programas verticais e recursos humanos formados em uma concepção contrária à almejada. Embora formalizado na Constituição, o SUS não conseguiu abandonar o modelo de seguros e programas públicos focalizados e se aproxima mais do 'universalismo básico', ao manter o sistema de seguros segmentados e não horizontalizar os programas verticais vigentes, como também demonstrado por Silva et al. (2009). Mas é fato que as propostas contidas nos marcos legais parecem direcionar para uma APS abrangente, fugindo do modelo seletivo e focalizado, que até pouco tempo parecia encaminhar as políticas de saúde do país. Assim, ao apontar e definir o caminho, o país demonstra uma ação transformadora que busca maior equidade para a população boliviana.

Sobre os processos de reforma orientados pela APS na América Latina, Labonté et al. (2009) ressaltam que é mais provável encontrar a APS integral nos países que possuem compromissos políticos com a equidade, um direito legal e constitucional à saúde garantido pelo Estado, e onde as políticas claramente identificam a atenção primária, a participação da comunidade e a ação intersetorial como componentes da APS. Os países analisados apresentam tais elementos nas reformas dos seus sistemas de saúde, com ênfases e graus variados, determinando como tendência a necessidade de aprofundamento das reformas com foco na APS abrangente. Como alertam Conill, Fausto e Giovanella (2010), após análise da integração da APS nos sistemas de saúde de alguns países da América Latina, apesar das mudanças em direção à universalização, problemas como a segmentação com fragmentação dos serviços permanecem presentes.

Em suma, o novo contexto político nos países analisados deslocou o foco das políticas para a universalização e para modelos assistenciais fundados em uma APS integral com avanços na última década. Em geral, foi possível observar mudanças constitucionais com afirmação do direito à saúde, inovaçóes importantes voltadas para implementação de uma APS abrangente e implementação incremental. No entanto, permanecem numerosos desafios relacionados ao contexto histórico institucional de cada um dos casos analisados a serem enfrentados para que ocorra a consolidação da APS nesses países como estratégia estruturante de seus sistemas de saúde.

\section{Referências}

ALMEIDA, M.H.T. A política social no governo Lula. Novos Estudos, São Paulo, n. 70, p.7-17, 2004.

ARNSON, C.; ARMONY, A. La nueva izquierda en América Latina: Derechos Humanos, Participación Política y Sociedad Civil. Woodrow Wilson Center Update on the Americas. Washington: Universidad Torcuato Di Tella., 2009.

BOLÍVIA. Constitución Politica del Estado Plurinacional de Bolivia, publicada em 07 de fevereiro de 2009. Disponível em: <http:// www.gacetaoficialdebolivia.gob.bo/edicions/view/NCPE>. Acesso em: 18 fev 2012.

Decreto Supremo no 29.601 de 11 de junho de 2008 Establece el Modelo de Atención y el Modelo de Gestión en Salud en el marco de la Salud Familiar Comunitaria Intercultural - SAFCI.
Disponível em: <http://www.gacetaoficialdebolivia.gob.bo/ normas/buscar/29601>. Acesso em: 18 fev 2012.

. Ministerio de Salud y Deportes. Sistema de Salud en Bolivia. La Paz: Sistema de Salud del Estado Plurinacional de Bolivia, 2011.

BONVECCHIO, A.; BECERRIL, V.; CARRIEDO, A. Sistema de Salud de Venezuela. Salud Pública de México, Morelos, v. 53, suppl. 2, p. 275286, 2011.

BRASIL. Constituição da República Federativa do Brasil: promulgada em 05 de outubro de 1988. Brasília: Senado Federal, 1988.

. Lei Orgânica da Saúde - Lei no 8.080, de 19 de setembro de 1990. Dispõe sobre as condições para a promoção, proteção e recuperação da saúde, a organização e o funcionamento dos 
serviços correspondentes e dá outras providências. Diário Oficial da União, Brasília, DF, 20 set. 1990, p. 18055.

Ministério da Saúde. Política Nacional de Atenção Básica. Brasília: Ministério da Saúde, 2006.

CASTRO, A.L.B. A condução federal da política de atenção primária à saúde no Brasil: continuidades e mudanças no período de 2003 a 2008. 2009. 215 p. Dissertação (Mestrado em Saúde Pública) Fundação Oswaldo Cruz, Escola Nacional de Saúde Pública Sergio Arouca, Rio de Janeiro, 2009.

CASTRO, A.L.B.; MACHADO, C.V. A política de atenção primária à saúde no Brasil: notas sobre a regulação e o financiamento federal. Cadernos de Saúde Pública, Rio de Janeiro, v. 26, n. 4, p. 693-705, 2010.

CONILL, E.M.; FAUSTO, M.C.R.; GIOVANELLA, L. Contribuições da análise comparada para um marco abrangente na avaliação de sistemas orientados pela atenção primária na América Latina. Revista Brasileira de Saúde Materno Infantil, Recife, v. 10, suppl. 1, p.15-27, 2010.

EUROSOCIAL SALUD. Dossier Nacional de Atención Primaria en Salud y la integración con otros niveles de atención. República de Uruguay. Elaborado por el equipo de técnicos del Proyecto Uruguay Saludable de la DIGESA y de la Sub-Dirección General de Atención Integral del Interior (ASSE). MSP - Uruguay, 2007.

FAUSTO, M.C.R. Dos programas de medicina comunitária ao Sistema Único de Saúde: uma análise histórica da atenção primária na política de saúde brasileira. 2005. 261 p. Tese (Doutorado em Saúde Coletiva) - Instituto de Medicina Social, Universidade do Estado do Rio de Janeiro, Rio de Janeiro, 2005.

GONZÁLEZ, M. Políticas de Salud en Venezuela: Ni lo urgente ni lo importante. Anales Venezolanos de Nutrición, Caracas, v. 18, n. 1, p. 39-44, 2005.

INSTITUTO SUL-AMERICANO DE GOVERNO EM SAÚDE (ISAGS). Sistemas de Salud en Suramérica: Desafíos para la universalidade, integralidade y equidade. Rio de Janeiro: ISAGS, 2011.

LABONTÉ, R. et al. Aplicación, efectividad y contexto político de la atención primaria integral de salud: resultados preliminares de una revisión de la literatura mundial. Revista Gerencia y Políticas de Salud, Bogotá, v. 8, n. 16, p.14-29, 2009.

LEDO, C.; SORIA, R. Sistema de salud de Bolivia. Salud Pública de México, Morelos, v. 53, suppl. 2, p. 109-119, 2011.

LUSTIG, N. Desigualdad y Pobreza bajo las nuevas izquierdas en América Latina. In: ARNSON, C.J.; JARA, J.; ESCOBAR, N. Pobreza, desigualdad y la "nueva izquierda" en América Latina. Woodrow Wilson Center Update on the Americas, Gobernabilidad Democrática y la 'Nueva Izquierda', n. 6, FLACSO Chile, 2009. p.5-10.
MACHADO, C.V. Prioridades da saúde no Brasil nos anos 90: três políticas, muitas lições. Revista Panamericana de Salud Pública, Washigton, v. 20, n. 1, p. 44-49, 2006.

MELLO, G.A.; FONTANELLA, B.J.; DEMARZO, M.M.P. Atenção Básica e Atenção Primária à Saúde: Origens e Diferenças Conceituais. Revista de APS, Juiz de Fora, v. 12, n. 2, p. 204-213, 2009.

MENY, I.; THOENIG, J.C. La dimensión comparativa de las políticas públicas. In: Meny, l.; Thoenig, J. C. Las políticas públicas. Barcelona: Ariel Ciência Política, 1992. p. 223-244.

MINISTERIO DEL PODER POPULAR PARA LA SALUD (MPPS). Informe ONU - Genebra. 2008. Disponivel em: <http://www.onuginebra.gob. ve/content/view/1>. Acesso em: 18 fev. 2012.

MOREIRA, C. Los dilemas de La Nueva Izquierda Gobernante en América Latina. Pensamento Plural, Pelotas, n. 1, p.49-64, 2007.

ORGANIZAÇÃO PAN-AMERICANA DA SAÚDE (OPAS). Renovação da Atenção Primária nas Américas. Documento de posicionamento. Washington: Panamerican Health Organization, PAHO/WHO, 2005.

Barrio Adentro: Derecho a la salud e inclusión social en Venezuela. Centro de Documentación e Información. Caracas: OPAS, 2006

PANIZZA, F. Nuevas Izquierdas y democracia en América Latina. Revista CIDOB dÁfers Internacionals, Barcelona, n. 85-86, p. 75-88, 2009.

PARODI, T. C. América Latina: Buscando el rumbo perdido. ICONOSFLACSO, Quito, n. 19, p. 35-42, 2004.

PAUSADELA, I. M. Las Izquierdas Latinoamericanas: de la oposición al Gobierno. Buenos Aires: CLACSO, 2010.

RED DE INVESTIGACIÓN EN SISTEMAS Y SERVICIOS DE SALUD EN EL CONO SUR DE AMÉRICA LATINA (RED). Atencion Primaria en Salud: modelos asistenciales, integracion al sistema de salud e intersectorialidad en contextos urbanos en Argentina, Brasil, Paraguay y Uruguay. Correo Salud, n. 12, 2009/2010.

RODRÍGUEZ, P. R. Venezuela: Del neoliberalismo al socialismo del siglo XXI. Revista Política y Cultura, Villa Quietud, n. 31, p. 187-211, 2010.

SAMPAIO, L.F.R. Debate sobre o artigo "Desafios para a organização de serviços básicos e da estratégia saúde da família". Cadernos de Saúde Pública, Rio de Janeiro, v. 24, suppl. 1, p.19-21, 2008.

SILVA, H.T. et al. Reformas de gobiernos socialistas a las políticas de salud en Bolivia y Ecuador: el potencial subestimado de la atención primaria integral de salud para impactar los determinantes sociales en salud. Medicina Social, Nova York, v. 4, n. 4, p. 272-282, 2009.

SOLLAZZO, A.; BERTERRETCHE, R. El Sistema Nacional Integrado de Salud en Uruguay y los desafíos para la Atención Primaria. Ciência \& Saúde Coletiva, Rio de Janeiro, v. 16, n. 6, p. 2829-2840, 2011. 
TEIXEIRA, C.F.; PAIM, J.S. A política de saúde no governo Lula e a dialética do menos pior. Saúdeem Debate, Londrina, v. 29, n. 71, p. 268-283, 2005.

VENEZUELA. Constitución de la República Bolivariana de Venezuela, publicada em 30 de dezembro de 1999. Disponível em: <http://pdba. georgetown.edu/constitutions/venezuela/ven1999.html>. Acesso em: 08 fev 2012.

VIANA, A.L.A.; DAL POZ, M.A. Reforma do Sistema de Saúde no Brasil e o Programa de Saúde da Família. Physis, Rio de Janeiro, v. 8, suppl. 2, p. $11-48,1998$.
WORLD HEALTH ORGANIZATION (WHO). Atenção primária à saúde: mais necessária que nunca. The World Health Report, 2008. Geneva: WHO, 2008.

Recebido para publicação em Maio/2012 Versão definitiva em Agosto/2012

Suporte financeiro: Teasdale-Corti Global Research Paternship Program; financiado pela Canadian Global Health Research Initiative. Conflito de interesses: Inexistente 